\title{
Depois da tempestade... Relato de um período de pandemia que abalou a bonança
}

Ana Aires, ${ }^{1}$ Cátia Almeida Oliveira ${ }^{1}$

\section{RESUMO}

No final do ano de 2019 surgiram na China os primeiros casos de uma infeção respiratória provocada por um vírus que viria a designar-se SARS-CoV-2 pela homologia com o coronavírus da síndroma respiratória aguda grave (SARS-CoV). A patologia causada pelo mesmo seria nomeada de COVID-19 ("COronaVirus Disease identified in 2019"), sendo que cerca de 80\% dos doentes infetados apenas apresentava sintomatologia ligeira. No entanto, pela sua infecciosidade, a doença rapidamente se disseminou por todos os continentes, apresentando uma mortalidade global de $5 \%$.

Desta forma, dado o aumento exponencial do número de doentes com COVID-19 por todo o mundo, em março de 2020 foi decretado o nível de pandemia, altura em que Portugal registou os primeiros casos. Pela imprevisibilidade e infecciosidade da doença, as autoridades políticas e de saúde do País foram obrigadas a implementar diversas medidas, tendo-se decretado inclusivamente uma cerca sanitária em Ovar após constatar-se a presença de transmissão comunitária ativa.

O presente relato de prática pretende refletir sobre o exercício da atividade clínica em período de pandemia por COVID-19. Trata-se de um relato de duas internas de medicina geral e familiar de uma Unidade de Saúde Familiar da zona de Ovar, com o intuito de, de algum modo, plasmar aquilo que terá sido a sua atividade assistencial neste período, em que a maioria dos contactos com utentes ocorreram de forma indireta. Com esta publicação pretende-se pensar sobre as dificuldades sentidas e o esforço realizado pela equipa de profissionais de saúde, à semelhança de tantas outras unidades de saúde de Portugal, com o objetivo de promover a manutenção da saúde, prevenção e gestão da doença de uma comunidade, em que os problemas, relativos ou não ao COVID-19, tivessem todos lugar num momento onde a pandemia era aparentemente a prioridade.

Palavras-chave: COVID-19; SARS-CoV-2; Cuidados de saúde primários; Portugal.

\section{ENQUADRAMENTO}

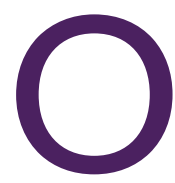
s primeiros casos de infeção pelo coronavírus relacionado à síndroma respiratória aguda grave 2 (SARS-CoV-2) surgiram em dezembro de 2019, na região de Wuhan, província de Hubei (China), onde vários doentes com diagnóstico de pneumonia foram admitidos nos hospitais locais. ${ }^{1}$

Inicialmente o agente etiológico não era conhecido, mas a doença rapidamente se disseminou na China e noutros países. Em 10 de janeiro de 2020, o vírus foi isolado de um doente com infeção respiratória do trato inferior e, após sequenciação do seu genoma, percebeu-se tratar-se de um novo tipo de coronavírus. No mês seguinte, um grupo de estudo da Comissão Interna-

1. USF Alpha, ACeS Baixo Vouga. Aveiro, Portugal. cional de Taxonomia dos Vírus denominou o novo vírus como SARS-CoV-2 e a Organização Mundial da Saúde (OMS) denominou a doença causada pelo mesmo como Doença Coronavírus 2019 (COVID-19). ${ }^{2}$

A infeção por SARS-CoV-2 apresenta um período de incubação estimado de um a catorze dias, sendo este mais frequentemente de quatro a cinco dias após a exposição. ${ }^{3} \mathrm{O}$ seu quadro clínico pode ser muito diverso, caracterizando-se por sintomas respiratórios, como tosse, dispneia e expetoração e sintomas constitucionais nomeadamente febre, astenia e mialgias. Menos frequentemente, pode cursar com sintomas gastrointestinais. ${ }^{4-5}$ Todas as pessoas que apresentem elevado grau de suspeição devem realizar teste para SARS-CoV-2, via deteção de RNA viral em amostras respiratórias. ${ }^{6}$

Em aproximadamente $80 \%$ das pessoas infetadas pela COVID-19, a doença é assintomática ou apresenta 


\section{N. ${ }^{\circ}$ de casos confirmados em Portugal}

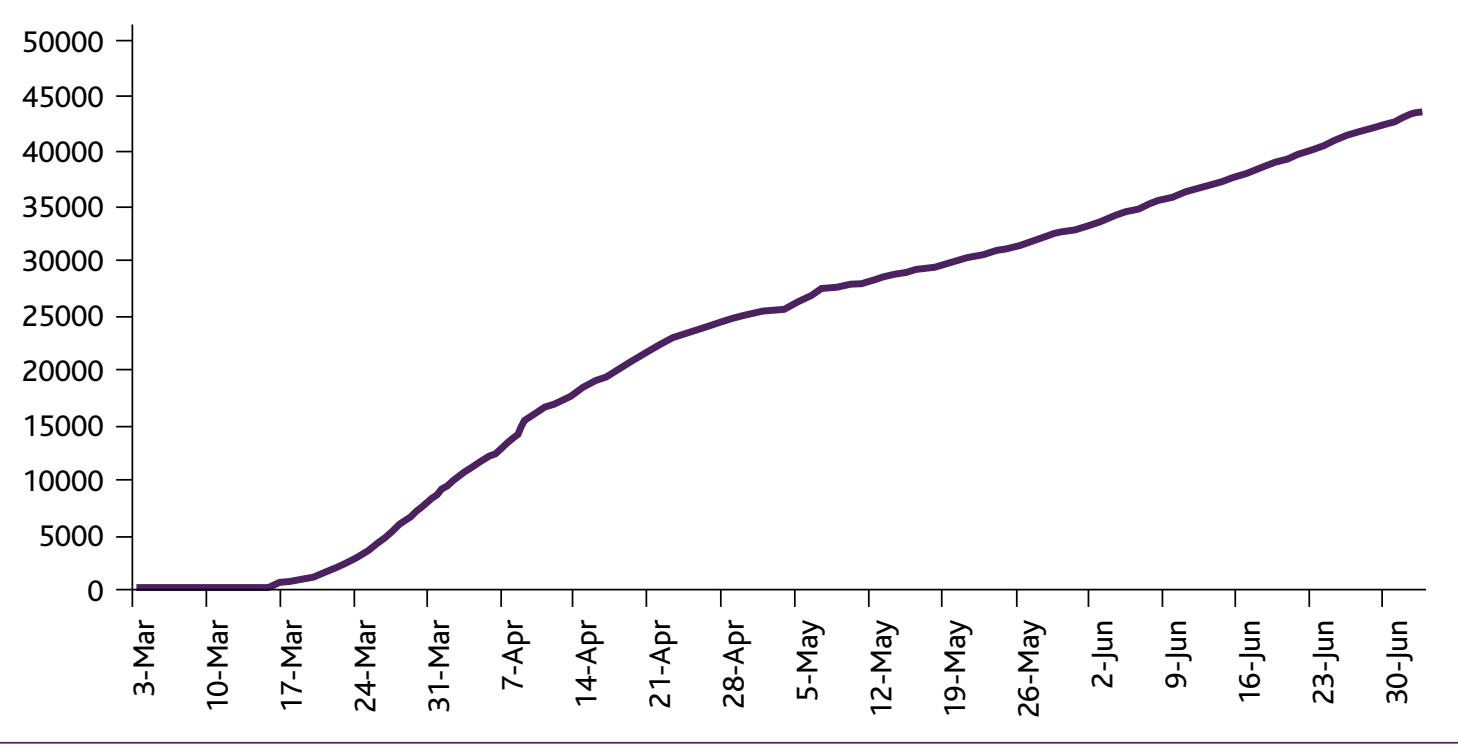

Figura 1. Situação epidemiológica em Portugal relativamente ao $n .^{\circ}$ de casos confirmados com SARS-CoV-2 no período de 3 de março a 3 de julho de $2020 .^{12}$

sintomatologia ligeira, ${ }^{4,7}$ sendo que cerca de $20 \%$ tem manifestações moderadas/graves e críticas. ${ }^{4}$ Com a experiência e conhecimentos adquiridos sobre esta patologia, precocemente percebeu-se que a gravidade da mesma estava relacionada com a existência de fatores de risco, nomeadamente idade ( $>60$ anos), doença cardiovascular, diabetes, hipertensão arterial, doença pulmonar crónica e imunossupressão. ${ }^{5}$ Os casos graves de doença podem cursar com pneumonia extensa, sinais de falência ventilatoria, disfunção multiorgânica ou choque e subsequente necessidade de admissão em unidade de cuidados intensivos. ${ }^{4}$ Deste modo, os doentes COVID-19 em estado crítico apresentam uma taxa de mortalidade variável que pode chegar a $97 \%$ em algumas séries. ${ }^{7}$

Quanto ao prognóstico da doença, ainda que habitualmente a evolução clínica seja favorável, é de algum modo muito variável mesmo sem fatores de risco, não sendo raros os casos de deterioração clínica entre o 7. ${ }^{\circ}$ e o $10 .^{\circ}$ dia da doença. Assim, estima-se que o tempo de recuperação seja de cerca de duas semanas na doença ligeira e de três a seis semanas na doença grave. ${ }^{6}$

À medida que iam sendo conhecidas mais informações sobre o vírus, rapidamente se percebeu tratar-se de uma patologia com alta infecciosidade e imprevisibilidade, para além de apresentar uma razoável mortalidade (cerca de 5\%) ${ }^{3,9}$ Assim, tendo por base estes conhecimentos, bem como o aumento rápido do número de casos fora da China, a 11 de março de 2020 a OMS anunciou que o surto tinha atingido o nível de pandemia. Até essa data foram reportados mais de 118.000 casos em 114 países. $^{8}$

Em Portugal, os primeiros casos confirmados de COVID-19 foram registados no dia 3 de março de 2020, ${ }^{9}$ sendo que o seu aumento, como noutros países, ocorreu de forma exponencial (Figura 1). Desta forma, a 18 de março de 2020, o Presidente da República declarou o estado de emergência, com efeitos imediatos a partir do dia seguinte à publicação do Decreto. ${ }^{10}$

O concelho de Ovar foi um dos mais afetados pela pandemia. Precocemente, a autoridade de saúde do município reconheceu a existência de uma situação epidemiológica compatível com transmissão comunitária ativa. Assim, a 17 de março foi declarado o estado de calamidade em Ovar com efeitos até ao dia 2 de abril. ${ }^{11}$ Pelos dados oficiais apresentados, a 23 de março de 2020 já se registavam 55 casos confirmados no 


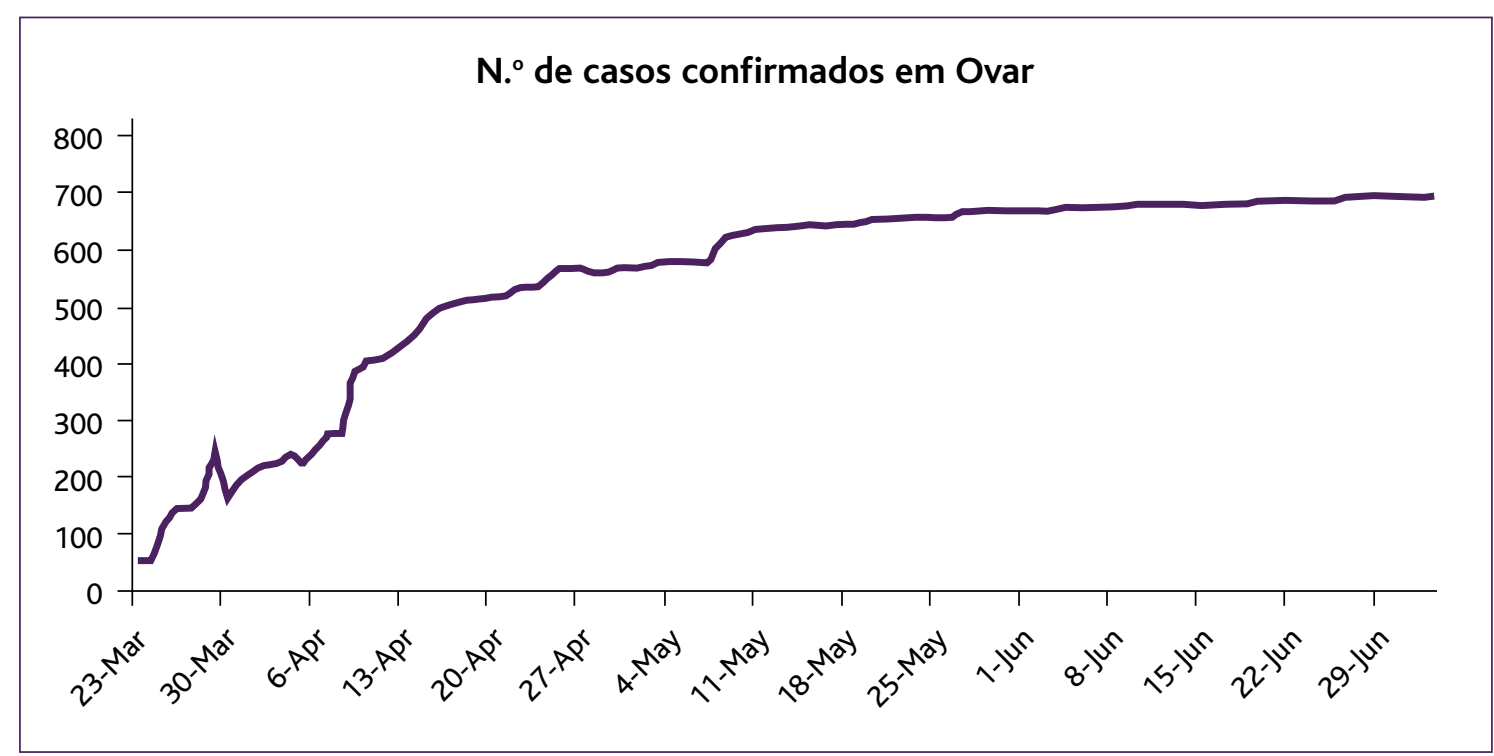

Figura 2. Situação epidemiológica em Ovar relativamente ao $n^{\circ}$ de casos confirmados com SARS-CoV-2 no período de 23 de março a 3 de julho de $2020 .^{12}$

concelho, ${ }^{12}$ sendo que nos dias seguintes, houve um aumento significativo no seu número (Figura 2).

Com a entrada em vigor deste despacho, que interditava a deslocação da comunidade vareira ou permanência na via pública, exceto para situações de primeira necessidade, ocorreu o encerramento de vários serviços públicos e de comércio e foi ainda impossibilitada a deslocação para os concelhos adjacentes, com a fixação de uma cerca sanitária. ${ }^{11}$

A 2 e 17 de abril de 2020, as autoridades nacionais, face ao panorama no País, decidiram a renovação do estado de emergência em Portugal. Apenas a 2 de maio de 2020, o País passou para o estado de calamidade, com apresentação de um plano de desconfinamento em três fases com vista à reabertura gradual de vários setores de atividade. ${ }^{13}$

Quanto à região de Ovar, o Conselho de Ministros prorrogou, a 2 de abril, os efeitos da declaração de situação de calamidade e a cerca sanitária no município até 17 de abril de 2020. ${ }^{14}$ Nessa data foram revogadas estas medidas; contudo, o novo decreto que renovou o estado de emergência do País apresentava um artigo onde estavam descritas as limitações especiais aplicáveis no concelho de Ovar. ${ }^{15}$

O presente relato de prática pretende refletir sobre uma realidade pessoal e profissional muito atual, viven- ciada por duas internas de medicina geral e familiar (MGF), que desempenham a sua atividade assistencial numa área rural em Ovar, face à pandemia pela COVID-19. Com o mesmo pretende-se retratar o papel que os cuidados de saúde primários tiveram e têm na prestação de cuidados à população no decorrer desta pandemia, bem como o trabalho desenvolvido e os desafios encontrados pelos profissionais de saúde na sua prática clínica diária, onde a manutenção da saúde, a cura e o tratamento da doença decorrem a par com a COVID-19.

\section{DESCRIÇÃO}

Ter-se-á o leitor alguma vez questionado "Qual o meu limite?”, ou já alguma vez terá visto algo no jornal ou na televisão e pensado: "Estas coisas só acontecem nos filmes e nunca em Portugal"? Com certeza que todos os médicos no mundo ter-se-ão questionado sobre estes e outros assuntos.

Duas internas de MGF, que trabalham numa Unidade de Saúde Familiar (USF) na zona rural de Ovar, desta vez não conhecida pelo seu mágico Carnaval, mas antes pela cerca sanitária, relatam a experiência que vivenciaram nesse período.

Com o surgimento dos primeiros casos confirmados de infeção em Portugal foi necessária a aplicação de 
um conjunto de medidas nas instituições de saúde. No caso particular desta USF foram estabelecidos procedimentos e circuitos, tendo por base as orientações emanadas pela Direção-Geral da Saúde (DGS). A primeira medida passou pela criação de uma equipa de trabalho, composta por um elemento de cada corpo clínico, para pensar e delinear as estratégias a implementar, de modo que os profissionais de saúde atuassem de forma célere e adequada perante um caso suspeito, com vista à prevenção e controlo da disseminação da infeção.

As estratégias inicialmente implementadas passaram pela sensibilização da população, através de cartazes informativos para desinfeção das mãos com solução antissética à entrada da USF, bem como avaliação da presença de sintomas, como tosse, febre ou dispneia. Se o utente fosse considerado caso suspeito deveria colocar uma máscara cirúrgica e seria encaminhado para o local de isolamento. De imediato a situação seria reportada ao médico para entrar em contacto com a Linha de Apoio ao Médico (LAM). Assim, surgiu um dos primeiros obstáculos. Apesar de o edifício ter sido inaugurado há cerca de dois anos, não apresentava nenhum gabinete com as características para a sala de isolamento proposta, nomeadamente ter uma casa de banho perto para uso exclusivo apenas do utente, paredes facilmente lavadas, mobiliário confortável e telefone.

Depois de algum tempo a refletir sobre este assunto e em concordância com a autoridade de saúde local, a solução passou por definir uma das casas de banho como sala de isolamento por cumprir os requisitos necessários para a mesma.

Se durante este processo a disseminação da doença parecia ainda distante e bastante controlável, não demorou muito tempo até que o dia-a-dia alterasse de forma radical e quase sem pré-aviso. Aproximadamente uma semana depois foi conhecido que, no concelho de Ovar, o número de casos de infeção era inestimável e as cadeias epidemiológicas estavam completamente perdidas, sendo por este motivo imperioso tomar uma atitude drástica, que passou pelo controlo apertado da entrada e saída dos utentes. Para isto, tendo em conta que a USF não dispõe de um segurança, a medida passou pelas secretárias clínicas realizarem este trabalho, sendo que para facilitar o mesmo a porta permanecia fechada, apenas sendo aberta a cada atendimento. A população inicialmente considerou que a USF estava fechada, mas através de uma adequada divulgação nas redes sociais, meios de comunicação social local (jornal e rádio) e cartazes em pontos estratégicos conseguiu-se transmitir que o método de trabalho tinha alterado. Foi privilegiado o contacto indireto, através de telefone ou mensagem de correio eletrónico, com necessidade de ajustes no modo de atuação dos profissionais de semana a semana, às vezes de dia para dia, até ao dia de hoje.

Talvez tenha sido esta altura que veio reforçar a importância de uma consulta e do contacto direto com o utente, acentuado, por seu turno, pela dificuldade na realização de uma teleconsulta. É verdade que uma boa história clínica permite obter $80-85 \%$ da informação necessária para o diagnóstico, sendo o restante obtido no exame físico e meios complementares de diagnóstico. ${ }^{16-17}$ Contudo, a realização da mesma também é suportada por uma comunicação eficaz, em termos de aquisição de linguagem não verbal, aquela que transmite sentimentos e emoções, seja ela postural, o aspeto, gestos, a mímica facial, a voz, o contacto visual ou o odor. Com a pandemia e o recurso à teleconsulta, tal qual uma pessoa que gradualmente aprimora outros sentidos quando perde a visão, também o médico foi adquirindo outras competências comunicacionais. Reforçou-se a importância da colheita da história clínica, com uma descrição detalhada dos sintomas, orientada pelo raciocínio clínico baseado nas diferentes hipóteses de diagnóstico, dados os sintomas apresentados. A voz passou a ter papel de destaque, estando o médico agora mais desperto para cada leve mudança de tom, riso, suspiro ou choro. Desta forma, os profissionais foram ganhando mais confiança na realização da teleconsulta, uma vez que estavam perante um novo paradigma, que exigiu uma mudança repentina e subsequente adaptação.

Por outro lado, também o utente teve necessidade de ajustes a esta nova realidade. Se anteriormente apenas conhecia o método de consulta presencial, com boa acessibilidade, que permitia que por um sinal ou sintoma recorresse à USF para ser observado pelo médico de família, na atualidade apenas tinha recurso aos meios eletrónicos. Para muitos, o simples facto de estar na presença física do «seu» médico e o mesmo 
ouvir as suas preocupações e esclarecer as suas dúvidas era a melhor e única intervenção terapêutica que necessitavam. Deste modo, tornou-se premente realizar uma gestão adequada dos sentimentos, emoções e expectativas do utente ao serem alvo de uma teleconsulta, em vez do método presencial, mostrando que, apesar de não estarem em presença física no consultório, podiam obter assistência da parte dos seus médicos. Tornou-se de extrema importância utilizar estes contactos com a USF para transmitir também os conhecimentos sobre o vírus e educar para as medidas e comportamentos que deviam ser adotados, de modo que os mesmos percebessem que era necessário mudar o modo de atuação.

Inicialmente, quando os números diariamente subiam, quando todas as pessoas conheciam um vizinho, um colega de trabalho, um amigo ou um familiar que tinha sido afetado pela infeção, o sentimento que reinava era o medo. Num primeiro momento, os contactos telefónicos eram muito direcionados para questões relacionadas com o vírus, nomeadamente se ao apresentarem determinada patologia podiam continuar a desempenhar a sua atividade laboral, que medidas deviam adotar para estarem mais protegidos e, no caso de apresentar um sintoma em particular, será que poderiam ter a doença... Outros sintomas e queixas, que não fossem do foro respiratório, foram deixadas para segundo plano.

Ao longo dos dias, a COVID passou a ter um lugar de destaque e, em todo lado, cresciam notícias e rúbricas sobre o tema. Precocemente as pessoas perceberam que estariam numa "guerra», contra um inimigo invisível (é certo) e, como tal, assumiram que deviam estar preparadas para o que havia de vir. Diariamente os números aumentavam e desassossegavam as mentes para um futuro incerto e conturbado. Em algum momento, as pessoas pensaram estar perto de um ponto de rutura, como se do fim de tudo no mundo se tratasse e, a cada dia, eram surreais as corridas ao papel higiénico e restantes bens de primeira necessidade nos supermercados. Pedidos de medicação crónica e de fármacos de tratamento sintomático, como paracetamol, aumentaram exponencialmente porque todos preparavam os seus suprimentos para o fecho completo de tudo, um confinamento obrigatório como acontecia em Itália. Neste país, o número de mortes tornou-se avassalador, com testemunhos dramáticos dos médicos sobre a escolha de quem teria acesso a ventiladores limitados, imprimindo o pânico em Portugal e permitindo ver onde não se queria chegar.

Com o número crescente de casos uma nova estratégia teve de ser delineada, uma vez que não existiam recursos nem capacidade para que todos os doentes infetados fossem internados em unidades hospitalares. Deste modo, e dado que $80 \%$ dos utentes apresentavam sintomatologia ligeira, ${ }^{4,7}$ a solução encontrada foi o isolamento dos doentes no domicílio. Assim, no momento em que era identificado um novo caso suspeito, no algoritmo de atuação existia uma secção dedicada às condições do domicílio, nomeadamente a presença de um quarto para uso exclusivo do utente. Era dada preferência à existência de uma casa de banho apenas para a pessoa, mas, no caso deste último requisito não se verificar, eram explicados os cuidados que deveriam ter antes e após a sua utilização. Neste momento era também realizado o ensino aos utentes sobre as medidas e cuidados de higiene que deveriam ser adotados por toda a família. No concelho de Ovar, à semelhança de outros locais no país, foi ainda destinado um edifício para acolher as pessoas que tinham critérios para permanecer no domicílio, mas não tinha condições estruturais. Relativamente à avaliação clínica destas pessoas, a mesma era realizada diariamente através de contacto telefónico pelo seu médico de família. Casos suspeitos ou confirmados de COVID-19 com fatores de risco ou gravidade clínica eram avaliados presencialmente em contexto de Áreas Dedicadas ao COVID (ADC) na comunidade, desde que sem critérios de gravidade para observação em contexto de serviço de urgência.

Neste sentido, novas orientações foram emanadas, bem como desenvolvida uma plataforma designada Trace COVID-19, uma ferramenta de registo de todos os utentes suspeitos e infetados com o intuito de auxiliar no seguimento dos mesmos. Assim, a partir deste momento, grande parte da atividade assistencial foi dedicada ao acompanhamento destes doentes, com médias de vigilância por unidade muito variáveis, de acordo com o período da pandemia a decorrer, tendo-se passado de 140 vigilâncias por dia no início de abril (para seis médicos e seis enfermeiros) para duas a três 
vigilâncias no fim de maio para a mesma unidade. Note-se que, com as medidas aplicadas, algumas pessoas residiram durante semanas, ou mesmo meses, num quarto apenas, em que a única deslocação permitida era a casa de banho, tudo isto com o intuito de evitar a contaminação de famílias inteiras. Numa revisão que avalia a transmissão da infeção por SARS-CoV-2 dentro do agregado familiar em vários países do mundo verificou-se que a média da percentagem de infeção dos membros da família, quando existe um caso positivo, é de cerca de $17 \%$. Contudo, destacou-se que existe variação entre as culturas, sendo este valor mais elevado nos países em que o número de co-habitantes é maior. ${ }^{18}$ Assim, os estudos mostram que o risco diminui com o rápido isolamento do elemento da família aquando da suspeita de infeção. ${ }^{19}$

Várias foram as famílias acompanhadas, tendo como exemplo uma composta por um agregado de sete pessoas, todos com COVID-19. Um dos elementos teve um episódio de perda de consciência, que motivou o encaminhamento para o serviço de urgência e subsequente internamento durante duas semanas em unidade de cuidados intensivos, com necessidade de ventilação assistida. Apesar de todo o agregado estar infetado, os efeitos do vírus não se fizeram sentir do mesmo modo. A sua imprevisibilidade e o seu tempo arrastado até à recuperação completa do doente em estado grave tornaram esta doença numa das maiores ameaças do momento.

Com o avançar da pandemia, além dos sintomas respiratórios, também os sinais de ansiedade e o medo da doença foram sendo cada vez mais frequentes. Os estados de ansiedade reativa, o medo de ficar infetado, o medo de sair à rua, entremeados por queixas sugestivas de causa psicossomática, tornaram-se cada vez mais frequentes. As teleconsultas seriadas e as reavaliações frequentes, com periodicidade variável de acordo com a patologia e numa gestão partilhada da situação, deram ao utente a confiança de que não estaria sozinho neste problema e capacitaram-no para que conseguisse também ele ultrapassar esta tempestade.

A verdade é que, por vezes, o utente, porque aos seus olhos as portas da USF se encontravam fechadas, pensou que o médico de família não teve qualquer papel no combate à pandemia. Pode assumir que o contacto telefónico, uma das formas preferenciais publicitadas pelos cuidados de saúde primários, é inalcançável. De facto, continuam a existir as mesmas linhas de telefone que existiam antes da pandemia COVID-19 quando o método de consulta se fazia presencialmente. Agora, médicos, enfermeiros e utentes lutam para conseguir uma linha de telefone livre, todos com o objetivo comum de ajudar e resolver o problema do utente. E se inicialmente o utente aceitou que a prioridade era a COVID-19, com o tempo considerou que os seus problemas não poderiam aguardar mais por um fim da pandemia, que não lhes parecia breve. Assim, médico, doente e COVID-19 viram-se, e talvez ainda se vejam, a levar a braços a saúde dos portugueses, num esforço que estranhamente nem sempre pareceu valorizado, ainda que bastante desgastante para os seus intervenientes. Ao utente, cada médico continuará a dizer que o responsável por todas as mudanças e os motivos pelos quais as coisas nunca mais serão iguais não é sua, não é propriamente de alguém, mas do que o COVID-19 veio alterar.

Para quem inicia o internato médico de MGF, muitas eram as espectativas, receios e medos perante esta caminhada na especialidade. Com a chegada da pandemia, a visão do futuro foi trocada pelo aqui e agora, pela informação mais atual relativamente ao vírus, pelas novas normas emanadas pela DGS, pelo novo procedimento e forma de atuação. As capacidades, competências e conhecimentos que deveriam ser adquiridos nesse período foram substituídos por outros, que fazem qualquer interno crescer, quer enquanto profissional quer enquanto pessoa.

Para quem já vai a meio desta caminhada, esperava-se que 2020 fosse um ano repleto de conquistas, tendo-se definido objetivos específicos para trabalhar e melhorar as capacidades na consulta. Este e outros objetivos ficaram suspensos, estando agora, a mais de meio do ano, a ser retomados.

Neste momento pode-se dizer que nenhum interno terá realizado aquilo que está escrito nos manuais, mas com certeza terá concretizado muito mais em termos comunicacionais, de relações humanas e em experiência de trabalho.

Constata-se, mais uma vez, que MGF é uma especialidade médica muito envolvente, exigente nas competências teóricas pela abrangência, não descurando aspetos como a empatia na relação médico-utente. 
Talvez seja das competências mais difíceis de dosear na especialidade. Não se trata de ser paternalista, nem de ter pena; trata-se de perceber as emoções do outro com base naquilo que são os seus fundamentos biopsicossociais. Com a pandemia realizaram-se inúmeras teleconsultas com utentes já conhecidos, outros que de quem se conhece apenas a voz e, com base apenas naquilo que os contactos telefónicos foram permitindo, a empatia construiu-se. Talvez nunca associem a cara à voz; contudo, em algum momento, as palavras que foram trocadas eram o que o utente precisava de ouvir, pois finalmente alguém, que nem ele sabe quem, o compreendeu.

\section{DISCUSSÃO}

E quanto ao futuro? É certo que com esta pandemia o método de trabalho mudou, tendo-se aprendido um sem fim de novas informações. Será que algum dia se irá voltar ao passado e à antiga forma de trabalhar?

$\mathrm{Na}$ opinião das internas isto seria um retrocesso. Apesar das limitações apresentadas pela teleconsulta (nomeadamente a impossibilidade de realização do exame físico, a incapacidade do utente conseguir expressar as suas queixas/problemas em situações clínicas mais complexas, a limitação da comunicação por via telefónica devido a hipoacusia, a dificuldade no acesso às novas tecnologias por parte da população mais idosa e a resistência dos doentes à mudança), há vantagens nesta nova realidade cujas potencialidades devem ser partilhadas com os utentes. Assim, destaca-se o facto de a teleconsulta diminuir o absentismo laboral, ser mais cómoda ao evitar deslocações e tempos de espera, diminuir o risco de contágio e, em alguns casos, facilitar abordagens de alguns temas que o utente não teria coragem de efetuar de forma presencial.

Por outro lado, apesar de nem sempre ser possível chegar a um diagnóstico ou definir um plano terapêutico apenas com a teleconsulta, esta permite realizar uma «triagem» das queixas e problemas do doente, antecipando a necessidade de exames auxiliares de diagnóstico, indispensáveis na decisão clínica, pois a realização do exame físico não permitiria obter esses achados. Assim sendo, relativamente ao relacionamento médico de família-doente que se pressupõe que seja um contacto de proximidade, onde as competências comunicacionais verbais e não verbais assumem des- taque, será que este método afasta ou aproxima o médico do utente?

No caso concreto da teleconsulta por motivo de doença aguda haverá diversas considerações a reportar. Num trabalho de investigação realizado na USF verificou-se que o médico de família do utente, quando o observa em contacto direto por patologia aguda, pelo conhecimento biopsicossocial deste indivíduo, elabora um plano terapêutico e orienta mais o utente para cuidados no domicílio e tratamentos de enfermagem em comparação com outro médico da unidade que o veja pelo mesmo motivo. Assim, a teleconsulta por doença aguda será, por extrapolação, mais facilmente conseguida quando ocorre com o médico de família do utente do que quando realizada por outro médico da unidade. Esta dificuldade deve-se, eventualmente, ao facto de não conhecer bem o utente, tendo uma maior necessidade de o observar presencialmente como complemento da teleconsulta. Por outro lado, neste tipo de consulta, de modo a estabelecer o diagnóstico e excluir outras hipóteses diagnósticas, poderá ser imprescindível a realização de exame físico, principalmente no sentido de identificar sinais de gravidade clínica.

Além disso, é fundamental perceber que existem serviços mínimos que em contexto de pandemia devem ter resposta, nomeadamente a vigilância de saúde infantil em períodos chave, como o primeiro ano de vida, a vigilância de saúde materna e a existência de pelo menos uma consulta presencial de vigilância de diabetes e hipertensão arterial, desde que o utente esteja compensado.

Quanto às consultas de saúde do adulto, muitas destinam-se a mostrar exames complementares de diagnóstico, pedidos previamente, consultas de reavaliação ou para abordar um problema de saúde/sinal ou sintoma de novo ou descompensação de patologia já conhecida. É fundamental, em mútuo acordo com o utente, perceber se a informação da teleconsulta é suficiente para se tomar uma atitude ou se é fundamental complementar com o exame objetivo, além de tentar perceber se o utente fica tranquilo e satisfeito com a avaliação telefónica ou se, por outro lado, aumentará a sua ansiedade e, subsequentemente, o recurso aos cuidados.

Deste modo, as reavaliações seriadas via teleconsulta ou de correspondência via $e$-mail acaba por tornar o 
médico mais próximo do seu utente e melhora a acessibilidade ao utente, bem como a segurança das decisões de ambos os intervenientes.

É necessário refletir que esta solução não será adequada a todos os tipos de utentes. Assim, cabe aos médicos estabelecer uma aliança terapêutica com os mesmos e, em conjunto, decidir a melhor forma de resolução do problema apresentado.

E quanto aos profissionais de saúde, será que estão dispostos a alterar as rotinas? E que custos isso terá para cada um?

Este método de trabalho, bem como as informações sobre o novo vírus, ainda é muito novo e apresenta pouca experiência no terreno. Assim, diariamente os profissionais são confrontados com algumas limitações e necessidade de alterações, com vista ao aprimoramento do mesmo. Todos os seres humanos têm alguma aversão à mudança e receio face ao desconhecido, pelo que mudar uma rotina diária, bem estabelecida e validada, para outra ainda em construção, exige um grande esforço por parte dos profissionais de saúde. Por outro lado, mudar não significa mais cansaço ou exaustão, trabalho acrescido ou preocupações crescentes. Mudar implica algo de novo e tal como, em bebé, se aprende a andar, passando depois a ser uma ação adquirida que se executa sem grande esforço, tudo o que é novo exige mais dispêndio de energia em profissionais já desgastados que precisam de voltar a sentir-se a entrar nos carris. Nuns novos carris, parece, mas tudo o que se quer é que a pilotagem pareça mais tranquila e se execute naturalmente. É, por isso, fundamental a reformulação de manuais de procedimentos das diversas atividades das USF, integrando as orientações já emanadas pela DGS e diversas Administrações Regionais de Saúde, de modo a contemplar neles os serviços mínimos em contexto de pandemia e abordando um modo de trabalho híbrido, adequado à realidade de cada USF.

Face a tudo o que foi exposto parece-nos coerente admitir que, no futuro, tendo em mente o tipo de doente e o seu superior interesse, se deve aliar ambos os métodos e usar as vantagens de cada um.

Quem sabe o leitor já se deparou várias vezes com estas e muitas outras questões. Talvez façam parte da sua reflexão diária ao avaliar a sua atividade profissional. As mesmas deixam alguma inquietude, com uma resposta mutável à medida que se vai avançando nesta experiência. A única certeza é que não existe uma resposta certa ou errada.

\section{REFERÊNCIAS BIBLIOGRÁFICAS}

1. Kannan S, Ali PS, Sheeza A, Hemalatha K. COVID-19 (novel coronavirus 2019): recent trends. Eur Rev Med Pharmacol Sci. 2020;24(4):200611.

2. She J, Liu L, Liu W. COVID-19 epidemic: disease characteristics in children. J Med Virol. 2020;92(7):747-54.

3. National Institutes of Health. Overview of COVID-19 [homepage]. $\mathrm{NIH} ; 2020$ [updated 2020 Dec 17]. Available from: https://www.covid19treatmentguidelines.nih.gov/overview/

4. Bajwah S, Wilcock A, Towers R, Costantini M, Bausewein C, Simon ST, et al. Managing the supportive care needs of those affected by COVID-19. Eur Respir J. 2020;55(4):2000815.

5. Guan WJ, Liang WH, Zhao Y, Liang HR, Chen ZS, Li YM, et al. Comorbidity and its impact on 1590 patients with Covid-19 in China: a nationwide analysis. Eur Respir J. 2020;55(5):2000547.

6. Centro Hospitalar Universitário do Porto. COVID-19 manual clínico [Internet]. Porto: CHUP; 2020.Available from: https://www.chporto.pt/pdf/ 2020/COVID-19_Manual_Clinico_CHUPorto.pdf

7. Weiss $P$, Murdoch DR. Clinical course and mortality risk of severe COVID-19. Lancet. 2020;395(10229):1014-5.

8. World Health Organization. Coronavirus disease (COVID-19) pandemic [homepage]. Copenhagen:WHO; 2020 [cited 2020 Jul 7]. Available from: https://www.euro.who.int/en/health-topics/health-emergencies/coronavirus-covid-19/novel-coronavirus-2019-ncov

9. Direção-Geral da Saúde. SARS-CoV-2/COVID-19: relatório de situação n 001 [homepage]. Lisboa: DGS; 2020 [cited 2020 Jul 7]. Available from: https://covid19.min-saude.pt/relatorio-de-situacao/

10. Decreto do Presidente da República n.o 14-A/2020, de 18 de março. Diário da República. $1^{\text {a }}$ Série(55 Supl 3).

11. Despacho n.o 3372-C/2020, de 17 de março. Diário da República. $2^{a}$ Série(54 Supl 3).

12. Direção-Geral da Saúde. Novo coronavírus COVID-19: relatório da situação [homepage]]. Lisboa: DGS; 2020 [cited 2020 Jul 7]. Available from: https://covid19.min-saude.pt/relatorio-de-situacao/

13. Assembleia da República. Estado de emergência - COVID-19 [homepage]. Lisboa: Assembleia da república; 2020 [cited 2020 Jul 7]. Available from: https://www.parlamento.pt/Paginas/covid19.aspx

14. Despacho n.o 4148-A/2020, de 5 de abril. Diário da República. $2^{\text {a Sé- }}$ rie(67-A Supl 1).

15. Decreto n.o 2-C/2020, de 17 de abril. Diário da República. $1^{\text {a }}$ Série(76 Supl 1).

16. Hampton JR, Harrison MJ, Mitchell JR, Prichard JS, Seymour C. Relative contributions of history-taking, physical examination, and laboratory investigation to diagnosis and management of medical outpatients. Br Med J. 1975;2(5969):486-9.

17. Summerton N.The medical history as a diagnostic technology. Br J Gen Pract. 2008;58(549):273-6.

18. Fung HF, Martinez L, Alarid-Escudero F, Salomon JA, Studdert DM, Andrews JR, et al. The household secondary attack rate of SARS-CoV-2): 
a rapid review. Clin Infect Dis. 2020 Oct 12. [Online ahead of print].

19. Grijalva CG, Rolfes MA, Zhu Y, McLean HQ, Hanson KE, Belongia EA, et al. Transmission of SARS-COV-2 infections in households:Tennessee and Wisconsin, April-September 2020. MMWR Morb Mortal Wkly Rep. 2020;69(44):1631-4.

\section{CONFLITO DE INTERESSES}

Os autores declaram não possuir quaisquer conflitos de interesse.

\author{
ENDEREÇO PARA CORRESPONDÊNCIA \\ Ana Aires \\ E-mail: anaaires1992@gmail.com \\ https://orcid.org/0000-0002-1288-6609
}

Recebido em 06-08-2020

Aceite para publicação em 07-02-2021

\section{ABSTRACT}

\section{AFTER THE STORM... A REPORT OF A PANDEMIC PERIOD BY COVID-19}

At the end of 2019 , the first cases of a respiratory infection caused by a virus appeared in China, which would later be called SARS-CoV-2 by its homology to severe acute respiratory syndrome coronavirus (SARS-CoV). The disease was called COVID-19 ('COronaVirus Disease identified in 2019 '), with nearly $80 \%$ of infected patients only presenting with mild or no symptoms. However, due to its infectiousness, the disease quickly spread to all continents, with an overall mortality of up to $5 \%$.

Thus, given the exponential increase in the number of patients with COVID-19 worldwide, in March 2020 the pandemic level was decreed, at the same time Portugal registered its first cases. Due to the unpredictability and infectiousness of the disease, the political and health authorities of our country were obliged to implement several measures, including a sanitary fence around Ovar after the presence of active community transmission.

This practice report aims to reflect on the clinical practice in a pandemic period by COVID-19. It is a first-person report of two-family medicine residents from a Primary Care Unit in the area of Ovar with the intention, in some way, of shaping what was their activity during this period, in which most of the contacts took place indirectly. With this publication, it is expected to think about the difficulties experienced and the effort made by health professionals, like so many other health units in Portugal, in order to promote the maintenance of health, prevention, and disease management in the community, in which the problems, related or not to COVID-19, had a prominent place at a time when the pandemic was apparently the priority.

Keywords: COVID-19; SARS-CoV-2; Primary health care; Portugal. 